\title{
Aerobic Training Improves Angiogenic Potential Independently of Vascular Endothelial Growth Factor Modifications in Postmenopausal Women
}

\author{
Pascal Izzicupo', Maria A. D'Amico', Andrea Di Blasio, Giorgio Napolitano, \\ Fabio Y. Nakamura, Angela Di Baldassarre* and Barbara Ghinassi
}

Department of Medicine and Aging Science, University "G. d'Annunzio" of Chieti - Pescara, Chieti, Italy

OPEN ACCESS

Edited by:

Maria Paula Gonçalves Mota, University of Trás-os-Montes and Alto

Douro, Portugal

Reviewed by: James Harper,

Sam Houston State University, United States

Carsten Merkwirth

Ferring Research Institute, Inc.,

United States

${ }^{*}$ Correspondence:

Angela Di Baldassarre

a.dibaldassarre@unich.it

tThese authors have contributed equally to this work.

Specialty section: This article was submitted to Endocrinology of Aging, a section of the journal Frontiers in Endocrinology

Received: 21 October 2017 Accepted: 11 December 2017 Published: 21 December 2017

Citation: Izzicupo P, D’Amico MA, Di Blasio A,

Napolitano G, Nakamura FY,

Di Baldassarre $A$ and Ghinassi $B$ (2017) Aerobic Training Improves Angiogenic Potential Independently of Vascular Endothelial Growth

Factor Modifications in

Postmenopausal Women.

Front. Endocrinol. 8:363. doi: 10.3389/fendo.2017.00363
Purpose: The purpose of this study is to evaluate the effect of walking-training on the balance between pro- and antiangiogenic signals and on the angiogenic potential in postmenopausal women.

Materials and methods: Thirty-four postmenopausal women (56.18 \pm 4.24 years) participated in a 13 weeks program of walking-training. Anthropometric measures, vascular endothelial growth factor (VEGF), interleukin (IL)-1 $\alpha, I L-1 \beta, I L-2, I L-8, I L-10, I L-12 p 70$, tumor necrosis factor- $\alpha$ (TNF- $\alpha$ ), C-reactive protein, insulin, IGF-1, cortisol, dehydroepiandrosterone sulfate (DHEA-S), leptin, visfatin, resistin, and adiponectin were evaluated before and after training. Moreover, serum samples were tested for their ability to chemoattract endothelial cells and to support the in vitro formation of capillary-like structures.

Results: After training, the levels of IL-8, TNF- $\alpha$, leptin, and resistin were significantly lower, levels of DHEA-S and adiponectin increased, serum angiogenic properties improved, whereas no changes in anthropometric parameters or VEGF were detected.

Conclusion: Walking training reduces inflammatory status and leads to a significant improvement in serum angiogenic properties in the absence of modifications in body composition and VEGF level.

Keywords: exercise, menopause, angiogenesis, adipokines, vascular endothelial growth factor, inflammation

\section{INTRODUCTION}

The decline of circulating levels of estrogen that characterizes the menopausal transition is associated with three closely related events that may lead to the onset and persistence of cardiovascular (CV) diseases: changes in body-fat distribution $(1,2)$, systemic low-grade inflammation (3), and endothelial dysfunction (4). Endocrinological changes seen in menopause also affect angiogenesis and estrogen reduction may impair the regenerative capacity of the CV system (5), thus contributing to the age-related microvascular rarefaction. Physical exercise is an effective non-pharmacological intervention for $\mathrm{CV}$ disease prevention. Indeed, habitual physical exercise is shown to strongly benefit health and longevity in humans likely due, at least in part, to its vasoprotective effects. The mechanisms of vasoprotection conferred by exercise are likely complex (6) but include a 
significant improvement of endothelial function, the induction of anti-inflammatory response and a positive influence on the number and/or function of endothelial progenitors cells. Postmenopausal women, however, tend to be less active $(2,7)$, and physical inactivity determines a persistent, sterile inflammation that is regarded to endothelial dysfunction and vascular alterations $(8,9)$. Moreover, physical inactivity is often associated with an excess of adipose tissue, which has been demonstrated to secrete increased amounts of the proinflammatory cytokines, including tumor necrosis factor- $\alpha$ (TNF- $\alpha)$, interleukin 1- $\beta$ (IL-1 $\beta$ ), and IL-6, thus contributing substantially to the chronic systemic inflammation. More recently, adipose tissue has been shown to be a source of additional molecules that operate at the interface between metabolism, immune responses and vascular health. In particular, leptin is an adipokine structurally similar to the IL-6 that modulates different physiological actions including food intake and angiogenesis sustaining, in parallel, a proinflammatory environment; similarly, resistin modulates several metabolic and inflammatory pathways and plays a role in atherogenesis, whereas on the contrary adiponectin plays an important role in maintenance of endothelial function, displaying anti-inflammatory, and antiatherogenic properties (10). The increase in fat mass is also associated with a relatively high level of vascular endothelial growth factor (VEGF) (11), a potent angiogenic molecule that was first described as an essential growth factor for vascular endothelial cells (12). VEGF is produced by many cell types, including endothelial, adipose and skeletal muscle cells $(13,14)$. Physical exercise induces an increment of VEGF that sustain the growth of new blood vessels in the trained muscles; on the other hand, the higher VEGF levels observed in obese subjects seems to be ineffective since adipose tissue appears hypoxic and undervascularized.

In the present study, we evaluated the effect of moderate-intensity walking training on angiogenic potential in postmenopausal women. Our hypothesis was that aerobic exercise might improve the angiogenic capacity by determining combined actions on hormones, cytokines, and adipokines.

\section{MATERIALS AND METHODS}

\section{Participants and Study Design}

The study was approved by the Ethical Committee of ChietiPescara University. The anthropometrical and physiological characteristics of the 34 postmenopausal women $(56.18 \pm 4.24$ years) enrolled in the study are reported in Table 1 . The inclusion criteria were: age $<65$ years; menses naturally ceased for at least 12 months, with plasma estradiol $<20 \mathrm{pg} / \mathrm{ml}$; body mass index (BMI) $>18.5$ and $<40 \mathrm{~kg} / \mathrm{m}^{2}$; no estrogen-replacement therapy; no history of orthopedic disease/dysfunction/injury that would impair walking. Further requirements were no participation in regular exercise programs for the past 6 months or in controlled diet programs in the past 2 years before enrollment. Participants provided written informed consent. Both medical examination and measurements were performed in the morning, in controlled temperature $\left(21-23^{\circ} \mathrm{C}\right)$ and humidity $(50 \%)$ (15). The basal screening $\left(T_{0}\right)$ consisted of anthropometric measurements and
TABLE 1 | Physiological and anthropometric characteristics of the samples.

\begin{tabular}{lc}
\hline & Mean \pm SD \\
\hline Age (years) & $56.18 \pm 4.24$ \\
BMl & $27.05 \pm 4.43$ \\
FM\% & $34.85 \pm 6.34$ \\
WC (cm) & $85.60 \pm 10.51$ \\
W/H ratio & $0.83 \pm 0.06$ \\
HR (bpm) & $66.71 \pm 8.18$ \\
SBP (mmHg) & $127.50 \pm 16.39$ \\
DBP (mmHg) & $80.00 \pm 8.26$ \\
TC (mg/dl) & $236.71 \pm 46.15$ \\
HDL (mg/dl) & $59.00 \pm 14.58$ \\
LDL (mg/dl) & $154.45 \pm 39.75$ \\
Triglycerides (mg/dl) & $114.03 \pm 71.34$ \\
\end{tabular}

$B M I$, body mass index; FM\%, fat mass percent; WC, waist circumference; W/H, waist to hip ratio; HR, heart rate; SBP, systolic blood pressure; $D B P$, diastolic blood pressure; TC, total cholesterol; HDL, high-density lipoprotein cholesterol; LDL, low-density lipoprotein cholesterol.

body composition analysis, a physical examination and a maximal aerobic-fitness test. A 12-h overnight fasting blood sample was drawn for the biohumoral determinations to characterize the metabolic, inflammatory and hormonal profiles of each menopausal woman. In particular, we measured: VEGF; a panel of proinflammatory cytokines, including IL-1 $\alpha$, IL-1 $\beta$, IL-2, IL-8, IL-10, IL-12p70, TNF- $\alpha$, and C-reactive protein (CRP); insulin and IGF-1 concentrations; dehydroepiandrosterone sulfate (DHEA-S); cortisol; and some selected adipokines (leptin, visfatin, resistin, and adiponectin). Furthermore, the sera of the postmenopausal women were tested for their ability to chemo-attract endothelial cells and to support the formation of capillary-like structures in vitro. The same tests were repeated for comparison after participation in the physical exercise program $\left(T_{1}\right)$. The study design did not include a control group since bioactive molecules such cytokines and adipokines are affected by exercise or dietary interventions while the absence of lifestyle modifications is associated with stable and relative high levels of inflammatory markers (16).

\section{Anthropometry and Body Composition}

All anthropometric measurements were performed by a specialist [level 3 certification of the International Society for the Advancement of Kinanthropometry (ISAK)]. Participants wore light clothing, had fasted, and had abstained from alcohol consumption from $48 \mathrm{~h}$ before the test. Body weight, stature, waist, and hip circumferences (WC and HC, respectively) were performed according to ISAK guidelines (17) using a stadiometer with a balance-beam scale and an anthropometric tape (Seca 200, Seca, Hamburg, Germany). BMI was calculated as weight (kilograms) divided by the square of stature (meters), whereas WC to HC ratio was calculated by dividing WC by HC. Body composition was assessed by the electrical bioimpedance technique using a foot-to-foot $50 \mathrm{kHz}$ frequency bioelectrical impedance scale (BC-420MA, Tanita, Tokyo, Japan). The test was performed after voiding, in an upright position, barefooted and without conducting garments. 


\section{Walking Training Eligibility, Aerobic Fitness Assessment, and Physical Exercise Program}

According to the American College of Cardiology/American Heart Association joint guidelines (15), walking training eligibility and aerobic fitness assessment of participants were assessed on the basis of the Astrand protocol through a graded maximal test on a cycle ergometer (SANA BIKE 150F, Ergosana GmbH, Bitz, Germany). During the test, heart rate and rhythm control were monitored by continuous electrocardiogram (AT-10 plus, SCHILLER, Baar, Switzerland), and blood pressure was measured throughout the test.

The intervention consisted of walking training 4 days/week for 13 weeks at moderate intensity. Exercise intensity was monitored on the basis of a 15-point rating scale of perceived exertion (RPE) (18). Participants were familiarized with the scale before and during the first week of the training. The intervention was divided in three mesocycles progressively more challenging: during the first and second months of training, participants walked at RPE level 11 for 40 and $50 \mathrm{~min} /$ day, respectively, whereas during the third month the intensity was raised to RPE level 12-13 for $50 \mathrm{~min}$. The walking training sessions were supervised and the compliance, calculated as the percentage of completed sessions to total sessions, was $81.9 \pm 18.2 \%$.

\section{Determination of Cytokine, Adipokine, and Hormone Levels}

Sera and plasma were obtained from 12 -h fasting blood samples and stored at $-80^{\circ} \mathrm{C}$ until analysis. Concentrations of plasma cytokines (IL-1 $\alpha$, IL-1 $\beta$, IL-2, IL-8, IL-10, IL-12p70, and TNF$\alpha$ ) were measured by the SearchLight Human Cytokine Array 1 (Aushon Biosystems, Billerica, MA, USA), whereas serum cortisol, estradiol, leptin, resistin, adiponectin, CRP, IGF-1, and DHEA-S levels were determined by enzyme-linked immunosorbent assays (DRG International Inc., Mountainside, NJ, USA). All samples were analyzed in duplicate during the same assay session.

\section{Endothelial Cell Migration and Tube Formation Assays}

The human umbilical vein endothelial cell (HUVEC) line and culture medium were purchased from Cell Applications (San Diego, CA, USA). The cells were cultured in DMEM/medium 199 (DMEM-199) 50:50 containing 20\% fetal calf serum (FCS), $2 \mathrm{mM}$ L-glutamine, $100 \mathrm{U} / \mathrm{ml}$ penicillin/streptomycin, $5 \mu \mathrm{g} / \mathrm{ml}$ fibroblast growth factor (Peprotech, Rocky Hill, NJ, USA) and $17.85 \mathrm{UI} / \mathrm{ml}$ heparin at $37^{\circ} \mathrm{C}$ and $5 \% \mathrm{CO}_{2}$. Before performing the migration and tube formation assays, cells were starved (3\% FCS in absence of fibroblast growth factor) for $5 \mathrm{~h}$.

The endothelial cell migration assay was performed using the BD BioCoat Angiogenesis System: Endothelial Cell Migration kit assay (Corning, New York, NY, USA). Briefly, $4 \times 10^{5} / \mathrm{ml}$ starved HUVECs were placed in the upper layer of the cellpermeable membrane, whereas a solution of DMEM-199 with $5 \%$ serum obtained from each woman before or after the intervention program $\left(T_{0}\right.$ and $\left.T_{1}\right)$ was placed in the chamber below.
VEGF (10 ng/ml) was used as the procedure control. After $22 \mathrm{~h}$ of incubation, cells that migrated through the membrane were stained with calcein AM $(8 \mu \mathrm{g} / \mathrm{ml}, \mathrm{BD})$, a fluorescent dye that specifically labels alive cells, and observed under a microscope and then quantified using a FC500 flow cytometer (Beckman Coulter, Indianapolis, IN, USA). At least three measurements were performed for each experimental condition.

For the tube formation assay, HUVECs $\left(4 \times 10^{5}\right.$ cells $\left./ \mathrm{ml}\right)$ were cultured on BD Matrigel matrix in DMEM-199 with 5\% serum obtained from each woman at $T_{0}$ and $T_{1}$. After $16 \mathrm{~h}$, endothelial cells were labeled with calcein AM $(8 \mu \mathrm{g} / \mathrm{ml}, \mathrm{BD})$ and observed with the DM IRB microscope (Leica) equipped with a Coolsnap video camera (Roper Scientific Photometrics, Tucson, AZ, USA). MetaMorph 6.1 Software (Universal Imaging Corp., Sunnyvale, CA, USA) was used to quantify the tube formation by measuring the width and the area covered by the capillary-like structures in $5 \times$ acquired images. In particular, for each sample the capillary width was calculated as the mean of five randomly selected fields (10 different measures per field), whereas the area was determined by thresholding the fluorescence of cells and then expressing as a percentage of the thresholded area (\% of surface covered by the capillary structures); for this evaluation, 10 measurements were performed for each experimental condition.

\section{Statistical Analysis}

Data were initially screened for normally with Shapiro-Wilk statistic. Pearson correlation coefficient was used to evaluate correlations between anthropometric and humoral parameters. Differences between $T_{0}$ and $T_{1}$ were tested by the paired-sample $t$-test. Data are presented as mean $\pm \mathrm{SD}$. The level of significance was set at $P \leq 0.05$.

\section{RESULTS}

\section{Determination of Cytokine, Adipokine, and Hormone Levels before and after the Walking Training}

We analyzed the VEGF level, a panel of proinflammatory cytokines, factors involved in glucose metabolism such as insulin and IGF-1, adrenal hormones (DHEA-S, cortisol), and some adipokines (leptin, visfatin, resistin, and adiponectin) (Table 2). All of these molecules affect inflammatory processes and influence the vascular health.

The walking training did not result in a significant change of body weight, anthropometric measures or lipid profiles, but it did alter some bio-humoral factors (Table 2). In particular, we detected a significant reduction of IL- 8 and TNF- $\alpha$. This alteration of the cytokine profile was accompanied by an increase in DHEA-S and by changes in adipokine concentrations, specifically a reduction in leptin and resistin and an increase in adiponectin. However, we did not detect a significant change in VEGF level.

Under basal conditions, VEGF level directly correlated with FM\%, BMI, WC, and leptin level (Figure 1). These correlations were not found after the intervention program. 
TABLE 2 | Cytokine, hormone, and adipokine levels before $\left(T_{0}\right)$ and after $\left(T_{1}\right)$ the intervention program.

\begin{tabular}{|c|c|c|c|c|c|}
\hline & & $T_{0}$ & $T_{1}$ & $t$ & $P$ \\
\hline Growth factor & VEGF (pg/ml) & $40.09 \pm 3.72$ & $41.44 \pm 6.77$ & -1.58 & $>0.05$ \\
\hline \multirow[t]{8}{*}{ Inflammatory cytokines } & $\| \mathrm{L}-1 \alpha(\mathrm{pg} / \mathrm{ml})$ & $8.98 \pm 13.44$ & $10.02 \pm 14.34$ & -0.57 & $>0.05$ \\
\hline & IL-1 $\beta(p g / m l)$ & $2.52 \pm 3.66$ & $1.91 \pm 2.51$ & 1.60 & $>0.05$ \\
\hline & IL-2 (pg/ml) & $79.37 \pm 46.81$ & $72.78 \pm 42.72$ & 1.08 & $>0.05$ \\
\hline & IL-8 (pg/ml) & $25.29 \pm 39.93$ & $19.29 \pm 28.13^{a}$ & 2.24 & 0.032 \\
\hline & IL-10 (pg/ml) & $4.44 \pm 4.19$ & $3.79 \pm 3.13$ & 0.89 & $>0.05$ \\
\hline & IL-12p70 (pg/ml) & $8.23 \pm 18.91$ & $8.06 \pm 11.96$ & 0.06 & $>0.05$ \\
\hline & TNF- $\alpha(p g / m l)$ & $42.60 \pm 31.25$ & $26.75 \pm 24.73^{a}$ & 3.26 & 0.003 \\
\hline & CRP (ng/ml) & $2933.54 \pm 5172.55$ & $1516.06 \pm 1656.92$ & 1.57 & $>0.05$ \\
\hline \multirow[t]{5}{*}{ Hormones } & Insulin (pg/ml) & $11.75 \pm 6.45$ & $12.64 \pm 8.24$ & -0.65 & $>0.05$ \\
\hline & IGF-1 (pg/ml) & $83.53 \pm 65.75$ & $98.49 \pm 104.23$ & -0.79 & $>0.05$ \\
\hline & DHEA-S (pg/ml) & $0.95 \pm 0.62$ & $1.13 \pm 0.75^{a}$ & -3.73 & 0.001 \\
\hline & Cortisol (pg/ml) & $126.48 \pm 55.50$ & $109.85 \pm 46.09$ & 1.83 & $>0.05$ \\
\hline & Estradiol (pg/ml) & $10.00 \pm 4.19$ & $10.41 \pm 3.23$ & -0.79 & $>0.05$ \\
\hline \multirow[t]{4}{*}{ Adipokines } & Leptin (pg/ml) & $57.34 \pm 26.72$ & $48.52 \pm 26.60^{a}$ & 3.18 & 0.003 \\
\hline & Visfatin (pg/ml) & $7.32 \pm 14.08$ & $7.71 \pm 7.39$ & -0.15 & $>0.05$ \\
\hline & Resistin (pg/ml) & $3.07 \pm 1.74$ & $2.24 \pm 2.03^{a}$ & 4.92 & $<0.001$ \\
\hline & Adiponectin (pg/ml) & $17.95 \pm 11.50$ & $25.75 \pm 16.92^{\mathrm{a}}$ & -3.59 & 0.001 \\
\hline
\end{tabular}

Data are expressed as mean $\pm S D$. Significance was set at $P<0.05$.

asignificantly different from $T_{0}$.

VEGF, vascular endothelial growth factor; IL, interleukin; TNF- $\alpha$, tumor necrosis factor alpha; CRP, C-reactive protein; IGF-1, insulin-like growth factor 1; DHEA-S,

dehydroepiandrosterone sulfate.
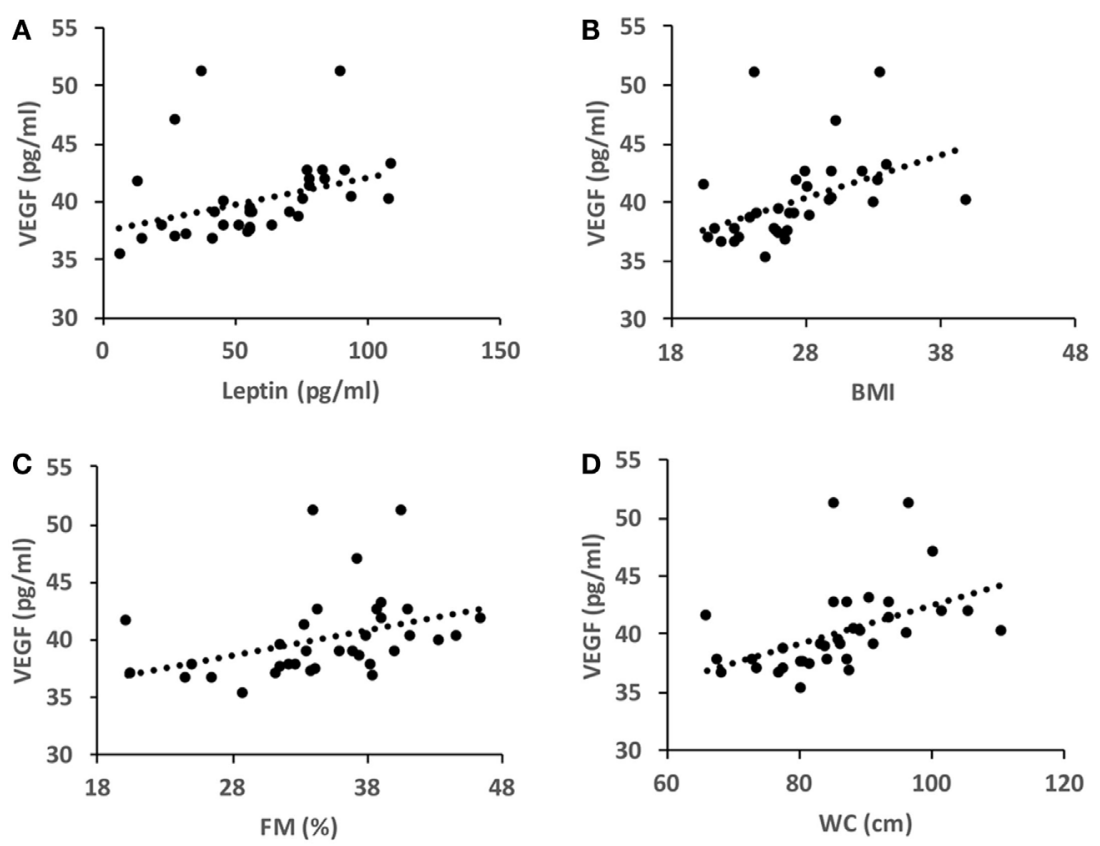

FIGURE 1 | Pearson's correlation coefficients in basal conditions $\left(T_{0}\right)$. (A) $r=0.343, P=0.047 ;$ (B) $r=0.438, P=0.01 ;$ (C) $r=0.468, P=0.005 ;$ (D) $r=0.361$, $P=0.036$. BMI, body mass index; WC, waist circumference; FM\%, fat mass percent.

\section{Angiogenic Potential of Serum before and after Training}

We analyzed the ability of the sera obtained before and after training to support angiogenesis by testing both the chemoattractive potential on endothelial cells and the ability to support the formation of capillary-like structures. It was found that walking training increased the chemoattractive potential of participants' sera, as the number of cells that migrated through the membrane was significantly greater in the presence of posttraining sera (Figure 2, a fold change of 0.5 between $T_{0}$ and $T_{1}$ sera). Similar results were obtained by analyzing the in vitro development of capillary-like structures. As showed in Figure 3, both tube width and the area 

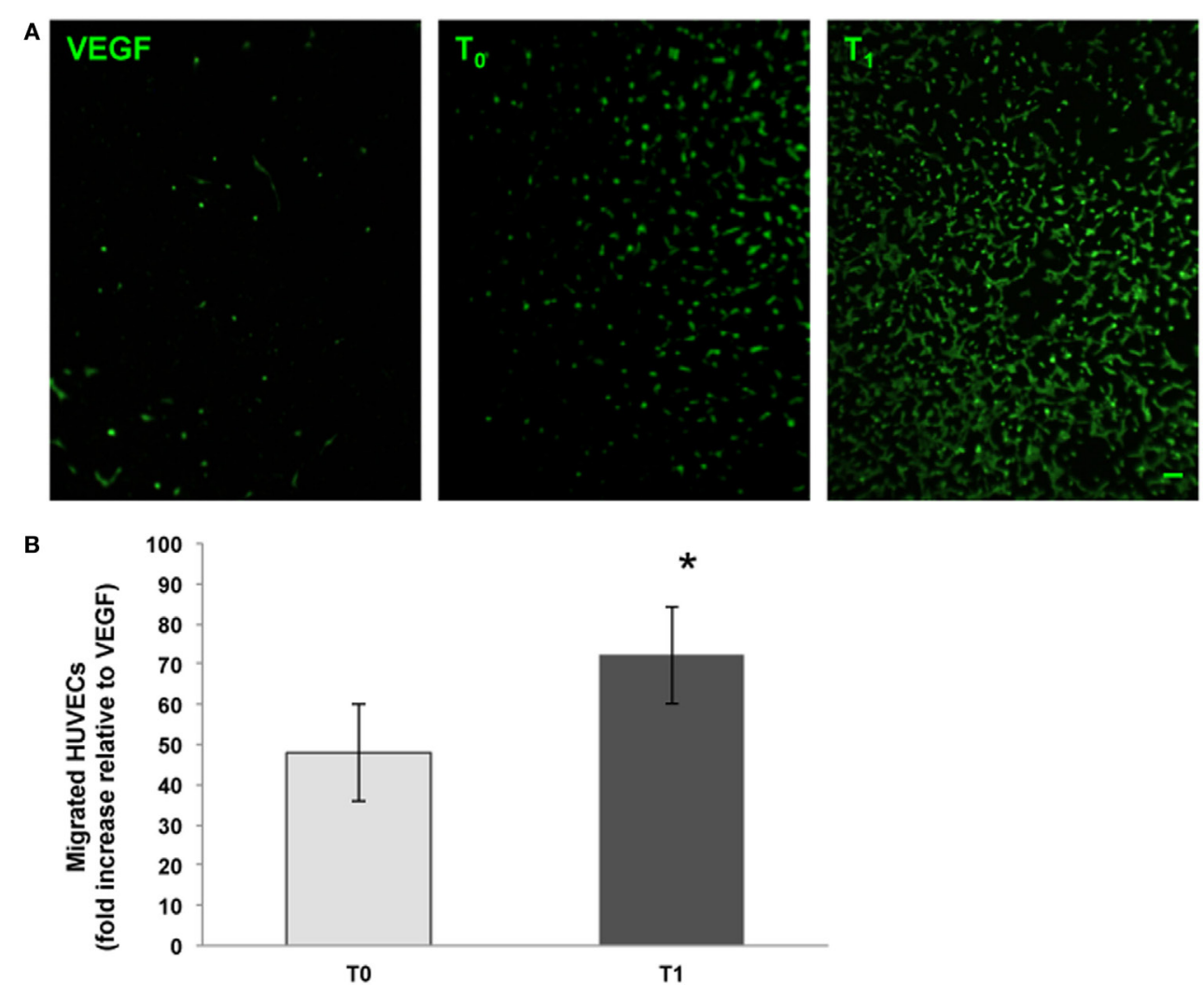

FIGURE 2 | Endothelial cell migration assays. The chemoattractive potential of serum obtained from menopausal women before ( $\left.T_{0}\right)$ and after ( $\left.T_{1}\right)$ training was assessed. Vascular endothelial growth factor (VEGF) (10 ng/ml) was used as procedure control. Human umbilical vein endothelial cells (HUVECs) that had migrated were stained with the vital dye calcein AM (green fluorescence). Original magnification: $20 \times$. Bar scale: $10 \mu \mathrm{m}$. The graph shows the number of migrated cells expressed as the fold increase relative to the control. *Significantly different from $T_{0}(t=-10.84, P<0.001)$.
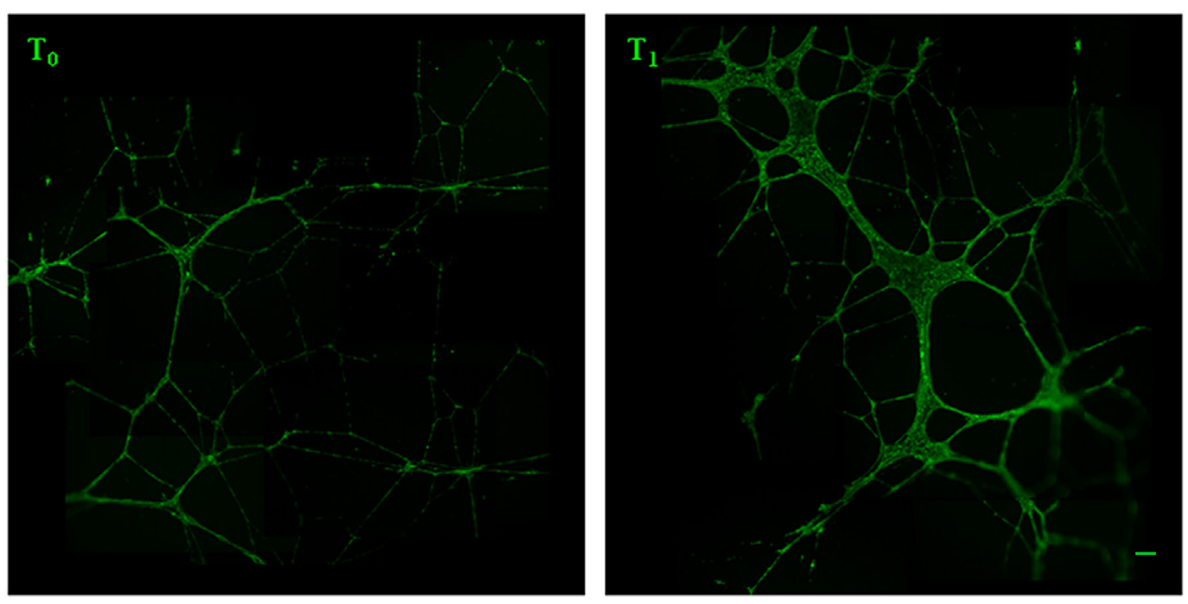

FIGURE 3 | Analysis of capillary-like tube formation. Human umbilical vein endothelial cells were cultured in Matrigel with $5 \%$ serum obtained from the women before $\left(T_{0}\right)$ and after $\left(T_{1}\right)$ the training period. After $16 \mathrm{~h}$, live endothelial cells were labeled with calcein AM (green fluorescence) and the tubes formation was analyzed by measuring the capillary-like structure width and area. Original magnification: $5 \times$. Bar scale: $40 \mu \mathrm{m}$. 
covered by capillary-like structures were significantly greater when endothelial cells were cultured in the presence of posttraining sera compared with pretraining sera (tube width: from $7.98 \pm 7.83$ to $18.25 \pm 16.86 \mu \mathrm{m}, t=-5.53, P<0.001$; area covered by tubes from $7.1 \pm 4.8$ to $16.99 \pm 8.43 \%, t=-11.62, P<0.001)$.

\section{DISCUSSION}

The main findings of this study are that: (i) in non-exercising postmenopausal women, VEGF concentration correlates with FM\%, BMI, WC and leptin; (ii) walking training induces a significant improvement in serum angiogenic properties affecting the molecular network that connect the immune, hormonal, and adipose factors without alteration in VEGF, body weight, or body-fat composition.

The association between adiposity and VEGF has been widely investigated in recent years (14). As in previous studies $(19,20)$, our data show that VEGF is directly correlated with FM\%, BMI, and WC. This observation is probably due to the fact that adipose tissue constitutively releases VEGF (21). VEGF sustains physiological angiogenesis during adipocyte expansion, whereas obesity is often characterized by hypoxic and undervascularized adipose tissue (22). This evidence suggests that VEGF efficacy is blunted in obese individuals whose adipose tissue is dysfunctional and inflammated (23). We also found for the first time to our knowledge, a direct correlation between VEGF and leptin. This finding is supported by the evidence that leptin stimulates VEGF synthesis via the JAK/STAT3 pathway (24). This observation contrasts with previous studies that did not find a correlation between VEGF and leptin; this discrepancy might be due to the fact that, in those other studies, the samples were heterogeneous for age and gender (18) or they were pathological samples (25).

After 13 weeks of walking training, we did not observe change in the weight or body fat distribution/composition of participants. This is unsurprising because walking training was the only experimental intervention, and compensation in both non-exercising physical activity and food intake could have prevented these effects (26). Nonetheless, physical exercise has several health benefits even in the absence of modification of anthropometric measures (27). Indeed, our data revealed an improvement in biohumoral factors, including significant reduction in the levels of TNF- $\alpha$, IL- 8 , leptin, and resistin and an increase in adiponectin and DHEA-S Adipokines are endocrine factors that regulate metabolic functions and influence inflammatory responses. In particular, leptin and resistin promote the inflammatory and atherosclerotic process, whereas adiponectin has an anti-inflammatory function by modulating TNF- $\alpha$ (14). DHEA-S, a precursor for estrogen and androgen production, declines progressively with age. Even if this reduction is not gender related, it appears to promote greater risk in postmenopausal women for the concomitant decline in ovary function and sex hormone deprivation. Previous findings (28) have demonstrated that DHEA-S affects atherosclerosis by improving endothelial cell growth and survival and inhibiting TNF- $\alpha$ production, which is a primary factor in endothelial dysfunction. Our data confirm that aerobic training may improve vascular health by interfering with the cross-talk among the hormonal factors and the inflammatory processes (29-32).

Results on the VEGF response to exercise are heterogeneous. Several studies showed that exercise increases circulating levels of VEGF $(33,34)$, but some others showed no effects or decreasing levels $(35,36)$. Wahl et al. (37) suggested that the VEGF response is dependent on the exercise intensity: lowintensity exercise causes no changes or a decrease, while higher intensities cause an increase in circulating VEGF levels. Besides the influence of exercise intensity, the variation on circulating VEGF levels seems to depend also on the training status, with VEGF modification observed in endurance-trained subjects, but not in sedentary individuals (33). Our data evidencing in sedentary menopausal women no modification of plasma VEGF levels after aerobic exercise at moderate intensity are consistent with these observations.

Menopause is a risk factor for $\mathrm{CV}$ disease because the estrogen withdrawal has a detrimental effect on CV function and metabolism (38). Estrogen delays endothelial cell senescence and is virtually involved in every aspect of the angiogenesis process since it promotes endothelial progenitor cell migration and proliferative capacity and increases telomerase activity of endothelial cells (39). As consequence, the endocrinological changes of menopause induce vascular dysfunction also impairing the regenerative capacity of the $\mathrm{CV}$ system (5), thus contributing to the age-related microvascular rarefaction and determining a reduction of tissue perfusion and blood-tissue exchange $(40,41)$. These effects are worsened by the proinflammatory microenvironment of the vasal walls that causes endothelial dysfunction, affecting cell proliferation/survival and increasing microvascular cell apoptosis (42). In this study, we observed that walking training, despite not affecting VEGF level, improved the serum angiogenic capacity of postmenopausal women. This finding seem to suggest that physical exercise might counteract the menopauserelated impairment of angiogenesis and microvascular rarefaction that contribute to a decline in peripheral blood flow and to a reduced perfusion at myocardial and cerebral levels (40). Because we found significant variation in cytokines, adipokines, and hormones but not VEGF modification, we hypothesize that the observed increased ability of serum to support angiogenesis after the intervention program may be ascribed, at least in part, to attenuation of the low-grade inflammation and hormonal and adipokine imbalances caused by the sex hormone deficiency.

\section{CONCLUSION}

In menopausal women, physical exercise might determine reduction in inflammation and improvement in tissue perfusion that are important targets in the prevention of $\mathrm{CV}$ and other non-communicable chronic diseases. This goal can be easily achieved through regular walking training performed at moderate intensity, according to the international physical activity guidelines (43). 


\section{ETHICS STATEMENT}

All subjects gave written informed consent in accordance with the Declaration of Helsinki. The protocol was approved by the Ethics Committee of the Chieti-Pescara University.

\section{AUTHOR CONTRIBUTIONS}

PI designed the work and performed the experiments. MD designed the work and performed the experiments. ADBl performed the experiments. GN designed the work and revised the manuscript. FN analyzed the data and revised the manuscript.

\section{REFERENCES}

1. Keller C, Larkey L, Distefano JK, Boehm-Smith E, Records K, Robillard A, et al. Perimenopausal obesity. J Womens Health (2010) 19:987-96. doi:10.1089/ jwh.2009.1547

2. Lovejoy JC, Champagne CM, de Jonge L, Xie H, Smith SR. Increased visceral fat and decreased energy expenditure during the menopausal transition. Int J Obes (Lond) (2008) 32:949-58. doi:10.1038/ijo.2008.25

3. Straub RH. The complex role of estrogens in inflammation. Endocr Rev (2007) 28:521-74. doi:10.1210/er.2007-0001

4. Chedraui P, Escobar GS, Pérez-López FR, Palla G, Montt-Guevara M, Cecchi E, et al. Angiogenesis, inflammation and endothelial function in postmenopausal women screened for the metabolic syndrome. Maturitas (2014) 77:370-4. doi:10.1016/j.maturitas.2014.01.014

5. Ballard V, Edelberg J. Harnessing hormonal signaling for cardioprotection. Sci Aging Knowledge Environ (2005) 2005(51):re6. doi:10.1126/ sageke.2005.51.re6

6. Di Francescomarino S, Sciartilli A, Di Valerio V, Di Baldassarre A, Gallina S. The effect of physical exercise on endothelial function. Sports Med (2009) 39:797-812. doi:10.2165/11317750-000000000-00000

7. McArthur D, Dumas A, Woodend K, Beach S, Stacey D. Factors influencing adherence to regular exercise in middle-aged women: a qualitative study to inform clinical practice. BMC Womens Health (2014) 14:49. doi:10.1186/ 1472-6874-14-49

8. Pedersen BK, Febbraio MA. Muscles, exercise and obesity: skeletal muscle as a secretory organ. Nat Rev Endocrinol (2012) 8:457-65. doi:10.1038/nrendo. 2012.49

9. Wagenmakers AJ, van Riel NA, Frenneaux MP. Integration of the metabolic and cardiovascular effects of exercise. In: Wagenmakers AJ, editor. The Biochemical Basis of the Health Effect of Exercise. London, GB: Portland Press (2006). p. 193-210.

10. Ouchi N, Parker JL, Lugus JJ, Walsh K. Adipokines in inflammation and metabolic disease. Nat Rev Immunol (2011) 11:85-97. doi:10.1038/nri2921

11. Christiaens V, Lijnen HR. Angiogenesis and development of adipose tissue. Mol Cell Endocrinol (2010) 318:2-9. doi:10.1016/j.mce.2009.08.006

12. Leung DW, Cachianes G, Kuang WJ, Goeddel DV, Ferrara N. Vascular endothelial growth factor is a secreted angiogenic mitogen. Science (1989) 246:1306-9. doi:10.1126/science.2479986

13. Hoier B, Prats C, Qvortrup K, Pilegaard H, Bangsbo J, Hellsten Y. Subcellular localization and mechanism of secretion of vascular endothelial growth factor in human skeletal muscle. FASEB J (2013) 27:3496-504. doi:10.1096/ fj. $12-224618$

14. Rodrigues T, Matafome P, Seiça R. A vascular piece in the puzzle of adipose tissue dysfunction: mechanisms and consequences. Arch Physiol Biochem (2013) 120:1-11. doi:10.3109/13813455.2013.838971

15. Swain D. ACSM's Resource Manual for Guidelines for Exercise Testing and Prescription. 9th ed. Philadelphia, PA: Wolters Kluwer Health/Lippincott Williams \& Wilkins (2014). 456 p.

16. Beavers KM, Nicklas BJ. Effects of lifestyle interventions on inflammatory markers in the metabolic syndrome. Front Biosci (Schol Ed) (2011) 3:168-77. doi: $10.2741 /$ s142
$\mathrm{ADBa}$ designed the work and wrote the manuscript. BG designed the work and wrote the manuscript.

\section{ACKNOWLEDGMENTS}

The authors are grateful to Dr. Simona Farinacci for her technical assistance.

\section{FUNDING}

This work was supported by a SIR grant from the Italian Ministry of Education, University and Research [grant number: RBSI140GLQ] .

17. Stewart A, Marfell-Jones M. International Standards for Anthropometric Assessment. Lower Hutt, New Zealand: International Society for the Advancement of Kinanthropometry (2011).

18. Borg G. Borg's Perceived Exertion and Pain Scales. Champaign, IL: Human Kinetics (1998). 104 p.

19. Miyazawa-Hoshimoto S, Takahashi K, Bujo H, Hashimoto N, Saito Y. Elevated serum vascular endothelial growth factor is associated with visceral fat accumulation in human obese subjects. Diabetologia (2003) 46:1483-8. doi:10.1007/s00125-003-1221-6

20. Gómez-Ambrosi J, Catalán V, Rodríguez A, Ramírez B, Silva C, Gil MJ, et al Involvement of serum vascular endothelial growth factor family members in the development of obesity in mice and humans. J Nutr Biochem (2010) 21:774-80. doi:10.1016/j.jnutbio.2009.05.004

21. Schlich R, Willems M, Greulich S, Ruppe F, Knoefel WT, Ouwens DM, et al. VEGF in the crosstalk between human adipocytes and smooth muscle cells: depot-specific release from visceral and perivascular adipose tissue. Mediators Inflamm (2013) 2013:1-10. doi:10.1155/2013/982458

22. Goossens GH, Bizzarri A, Venteclef N, Essers Y, Cleutjens JP, Konings E, et al. Increased adipose tissue oxygen tension in obese compared with lean men is accompanied by insulin resistance, impaired adipose tissue capillarization, and inflammation. Circulation (2011) 124:67-76. doi:10.1161/ circulationaha.111.027813

23. Sun K, Asterholm IW, Kusminski CM, Bueno AC, Wang ZW, Pollard JW, et al Dichotomous effects of VEGF-A on adipose tissue dysfunction. Proc Natl Acad Sci U S A (2012) 109:5874-9. doi:10.1073/pnas.1200447109

24. Cao Y. Angiogenesis modulates adipogenesis and obesity. J Clin Invest (2007) 117:2362-8. doi:10.1172/jci32239

25. García dela TorreN, Rubio MA,BordiúE,Cabrerizo L, AparicioE, HernándezC, et al. Effects of weight loss after bariatric surgery for morbid obesity on vascular endothelial growth factor-A, adipocytokines, and insulin. J Clin Endocrinol Metab (2008) 93:4276-81. doi:10.1210/jc.2007-1370

26. Izzicupo P, D’Amico MA, Bascelli A, Di Fonso A, D’Angelo E, Di Blasio A, et al. Walking training affects dehydroepiandrosterone sulfate and inflammation independent of changes in spontaneous physical activity. Menopause (2012) 20:455-63. doi:10.1097/gme.0b013e31827425c9

27. Di Blasio A, Ripari P, Bucci I, Di Donato F, Izzicupo P, D’Angelo E, et al. Walking training in postmenopause. Menopause (2012) 19:23-32. doi:10.1097/ gme.0b013e318223e6b3

28. Nheu L, Nazareth L, Xu GY, Xiao FY, Luo RZ, Komesaroff P, et al. Physiological effects of androgens on human vascular endothelial and smooth muscle cells in culture. Steroids (2011) 76:1590-6. doi:10.1016/j.steroids.2011.09.015

29. Gallina S, Di Francescomarino S, Di Mauro M, Izzicupo P, D’Angelo E, D'Amico MA, et al. NAD(P)H oxidase p22phox polymorphism and cardiovascular function in amateur runners. Acta Physiol (Oxf) (2012) 206:20-8. doi:10.1111/j.1748-1716.2012.02456.x

30. Izzicupo P, Ghinassi B, D’Amico MA, Di Blasio A, Gesi M, Napolitano G, et al. Effects of ACE I/D polymorphism and aerobic training on the immuneendocrine network and cardiovascular parameters of postmenopausal women. J Clin Endocrinol Metab (2013) 98:4187-94. doi:10.1210/jc.2013-2305

31. Di Mauro M, Izzicupo P, Santarelli F, Falone S, Pennelli A, Amicarelli F, et al. ACE and AGTR1 polymorphisms and left ventricular hypertrophy in 
endurance athletes. Med Sci Sports Exerc (2010) 42:915-21. doi:10.1249/ mss.0b013e3181c29e79

32. Izzicupo P, Di Valerio V, D’ Amico MA, Di Mauro M, Pennelli A, Falone S, et al. $\mathrm{NAD}(\mathrm{P}) \mathrm{H}$ oxidase and pro-inflammatory response during maximal exercise: role of C242T polymorphism of the P22PHOX subunit. Int I Immunopathol Pharmacol (2010) 23:203-11. doi:10.1177/039463201002300118

33. Kraus RM, Stallings HW III, Yeager RC, Gavin TP. Circulating plasma VEGF response to exercise in sedentary and endurance-trained men. J Appl Physiol (2004) 96:1445-50. doi:10.1152/japplphysiol.01031.2003

34. Van Craenenbroeck EM, Vrints CJ, Haine SE, Vermeulen K, Goovaerts I, Van Tendeloo VFI, et al. A maximal exercise bout increases the number of circulating CD34/KDR endothelial progenitor cells in healthy subjects. Relation with lipid profile. J Appl Physiol (2004) 104:1006-13. doi:10.1152/ japplphysiol.01210.2007

35. Adams V, Linke A, Breuckmann F, Leineweber K, Erbs S, Kränkel N, et al. Circulating progenitor cells decrease immediately after marathon race in advanced-age marathon runners. Eur J Cardiovasc Prev Rehabil (2008) 15:602-7. doi:10.1097/HJR.0b013e328309c756

36. Gu JW, Gadonski G, Wang J, Makey I, Adair TH. Exercise increases endostatin in circulation of healthy volunteers. BMC Physiol (2004) 4:2. doi:10.1186/1472-6793-4-2

37. Wahl P, Zinner C, Achtzehn S, Behringer M, Bloch W, Mester J. Effects of acid-base balance and high or low intensity exercise on VEGF and bFGF. Eur J Appl Physiol (2011) 111:1405-13. doi:10.1007/s00421-010-1767-1

38. Rosano GM, Vitale C, Marazzi G, Volterrani M. Menopause and cardiovascular disease: the evidence. Climacteric (2007) 10:19-24. doi:10.1080/ 13697130601114917

39. Lähteenvuo J, Rosenzweig A. Effects of aging on angiogenesis. Circ Res (2012) 110:1252-64. doi:10.1161/CIRCRESAHA.111.246116
40. Ungvari Z, Kaley G, de Cabo R, Sonntag WE, Csiszar A. Mechanisms of vascular aging: new perspectives. J Gerontol A Biol Sci Med Sci (2010) 65:1028-41. doi:10.1093/gerona/glq113

41. Levy BI, Schiffrin EL, Mourad JJ, Agostini D, Vicaut E, Safar ME, et al. Impaired tissue perfusion a pathology common to hypertension, obesity, and diabetes mellitus. Circulation (2008) 118:968-76. doi:10.1161/ CIRCULATIONAHA.107.763730

42. van den Oever IA, Raterman HG, Nurmohamed MT, Simsek S. Endothelial dysfunction, inflammation, and apoptosis in diabetes mellitus. Mediators Inflamm (2010) 2010:792393-408. doi:10.1155/2010/ 792393

43. Haskell WL, Lee IM, Pate RR, Powell KE, Blair SN, Franklin BA, et al. Physical activity and public health: updated recommendation for adults from the American College of Sports Medicine and the American Heart Association. Med Sci Sports Exerc (2007) 39:1423-34. doi:10.1249/ mss.0b013e3180616b27

Conflict of Interest Statement: The authors declare that the research was conducted in the absence of any commercial or financial relationships that could be construed as a potential conflict of interest.

Copyright $\odot 2017$ Izzicupo, D’Amico, Di Blasio, Napolitano, Nakamura, Di Baldassarre and Ghinassi. This is an open-access article distributed under the terms of the Creative Commons Attribution License (CC BY). The use, distribution or reproduction in other forums is permitted, provided the original author(s) or licensor are credited and that the original publication in this journal is cited, in accordance with accepted academic practice. No use, distribution or reproduction is permitted which does not comply with these terms. 